\title{
Some Suggestions on the construction of Planning Environmental Impact Assessment system
}

\author{
Zhang Mingbo ${ }^{1, a}$, Zhang Yifei ${ }^{1, b}$ and Shi Jingang ${ }^{1, c}$ \\ ${ }^{1}$ Environmental Development Centre of Ministry of Environmental Protection, Yuhuinanlu \\ No.1,Chaoyang District, Beijing, China \\ azhangmingbo@edcmep.org.cn, bzhangyifei@edcmep.org.cn, cshijingang@edcmep.org.cn
}

\begin{abstract}
Keywords: Planning Environmental Impact Assessment System, Planning Environmental Impact Assessment, Tracking Evaluation, Verification Regime

Abstract. In this paper, one typical case of industrial park was studied deeply. Based on the research of development history, planning and planning environmental impact assessment, the pollutant emissions, the environmental quality and the health of the surrounding population of typical case, some suggestions on the construction of planning environmental impact assessment system including planning environmental impact assessment, planning environmental impact assessment tracking evaluation and verification regime were provided.
\end{abstract}

\section{Introduction}

Environmental Impact Assessment (EIA) is a process evaluating the effects of a proposed project, plan or activity on the environment. It has been thirty-nine years since EIA was formally introduced in China in 1979 through inclusion in the Environmental protection law of the People's Republic of China (for trial implementation) ${ }^{[1]}$. Planning Environmental Impact Assessment (Planning EIA) has been formally incorporated into the regulatory system for 15 years. As an important component of environmental management, Planning EIA plays an important role in controlling pollutant emission, improving environmental quality and optimizing industrial layout ${ }^{[2]}$. However, in the process of executing, Planning EIA is unable to play its proper role due to the intervention time is too late $\mathrm{e}^{[3]}$, imperfect evaluation technology ${ }^{[4]}$, the analysis about capacity of natural environment is not deep ${ }^{[5]}$, thus restricting the promotion and development of the system. A relative perfect system should be built to help ensure provisions of the Planning EIA are implemented. Therefore, we choose one typical case of industrial park to study deeply.

\section{Case analysis and discussion}

Founded in 1992, with a planning area of $8.32 \mathrm{~km}^{2}$, A nonferrous metal industrial park specialized in $\mathrm{Pb}$ smelting and deep-processing was used as a typical case. There are 19 manufacturing projects in the area, among which 9 companies are involved in $\mathrm{Pb}$ smelting and deep-processing enterprises. Among them, the output of crude lead was $80,000 t / a$, electrolytic lead was $152,000 t / a$, regenerated lead was $54,000 t / a$, and yellow lead was 7600t/a.

After nearly 20 years extensive development, In 2010, the lead emissions were once as high as 59.78t/a. In order to understand the impact of lead on the surrounding population, in 2011, blood sampling on blood lead concentrations was conducted on the surrounding population of the industrial park. A total of 169 people were sampled, including 79 in child group and 90 in adult group. The results showed that: the proportion of children with high lead levels reached $21.5 \%$, for adults, it was $25.6 \%$. The total ratio is $23.7 \%$. The highest blood lead concentration was $525.06 \mu \mathrm{g} / \mathrm{L}$. The results were shown as followed in figure 1.

In order to reduce the emission of lead, in 2011, the master plan was worked out. The same year, the planning EIA report was reviewed by the local competent administrative department of environmental protection. In the master plan and planning EIA report, a variety of measures were introduced, such as forcing elimination of the laggard, pollutant-discharge units being ordered to handle their pollution problems by a prescribed time should make periodic reports to environmental protection authorities on 
the progress made, the dust collecting system was modified to remove the heavy metal pollutants such as lead and zinc cadmium and the management and equipment was effectively strengthened to reduce the heavy metal exhaust emissions.

Through efforts over 5 years, the same blood sampling on blood lead concentrations was conducted in 2017. A total of 179 people were sampled, including 26 in child group and 153 in adult group. The results showed that: the proportion of children with high lead levels reached 50\%, no adult has reached the standard of high lead levels, the total ratio is $7 \%$. The highest blood lead concentration was $342.9 \mu \mathrm{g} / \mathrm{L}$. The results were shown as followed in figure 2 . Through efforts over 5 years, the proportion of people with high lead levels went down from $23.7 \%$ to $7 \%$. The highest blood lead concentration went down from an initial $525.06 \mu \mathrm{g} / \mathrm{L}$ to $342.9 \mu \mathrm{g} / \mathrm{L}$ (see figure 3 ). A series of measures have made a distinct improvement in the health of the surrounding population.

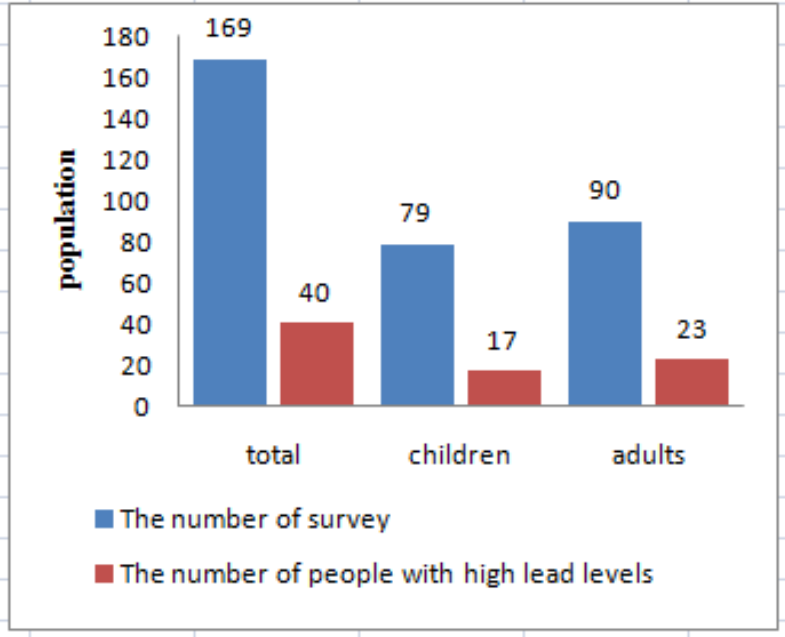

Fig 1 the survey results in 2011

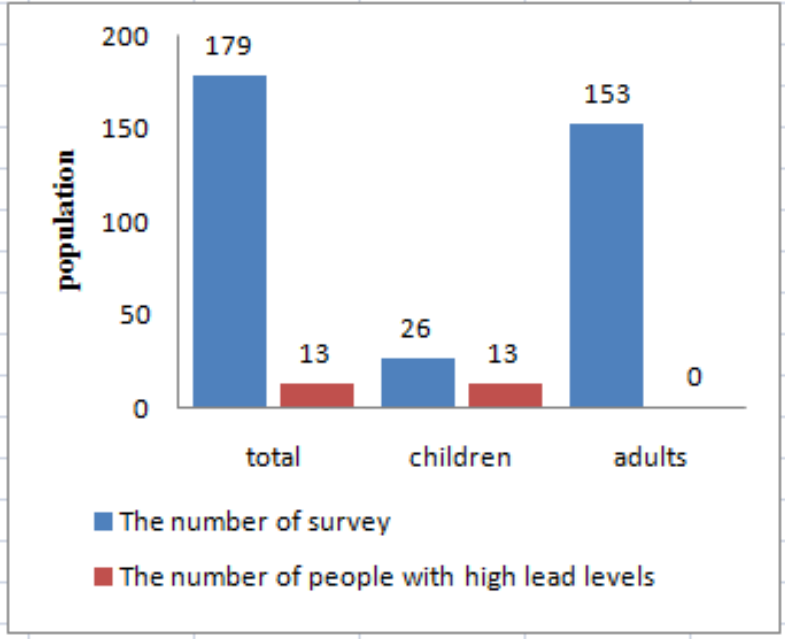

Fig 2 the survey results in 2017

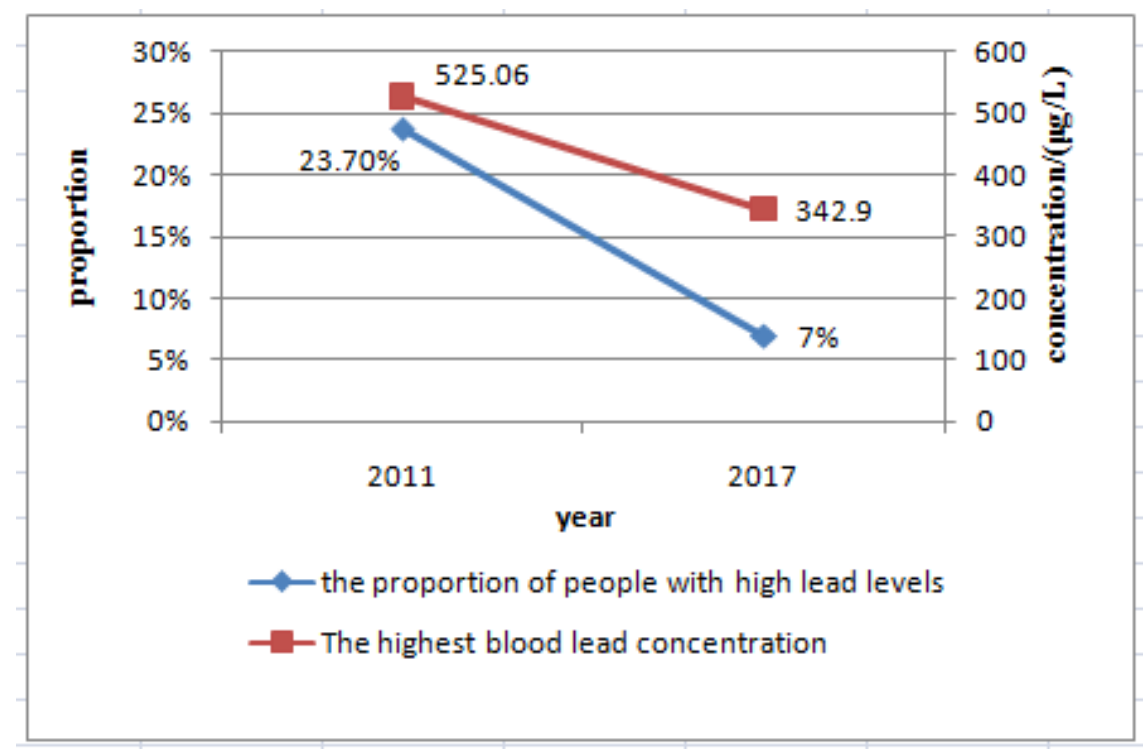

Fig 3 the changing trends of the two surveys

The emissions and the monitoring data of lead over a series of years were analyzed (see figure 4and figure 5). The lead emissions have been cut from59.78t/a to 10.63t/a form 2010 to 2016. The cut was as high as $82.22 \%$.Lead concentrations in the atmosphere have also cut from $1.6735 \mu \mathrm{g} / \mathrm{m}^{3}$ to $0.86 \mu \mathrm{g} / \mathrm{m}^{3}$. Much of the improvement in the health of the surrounding population was due to these changes. 


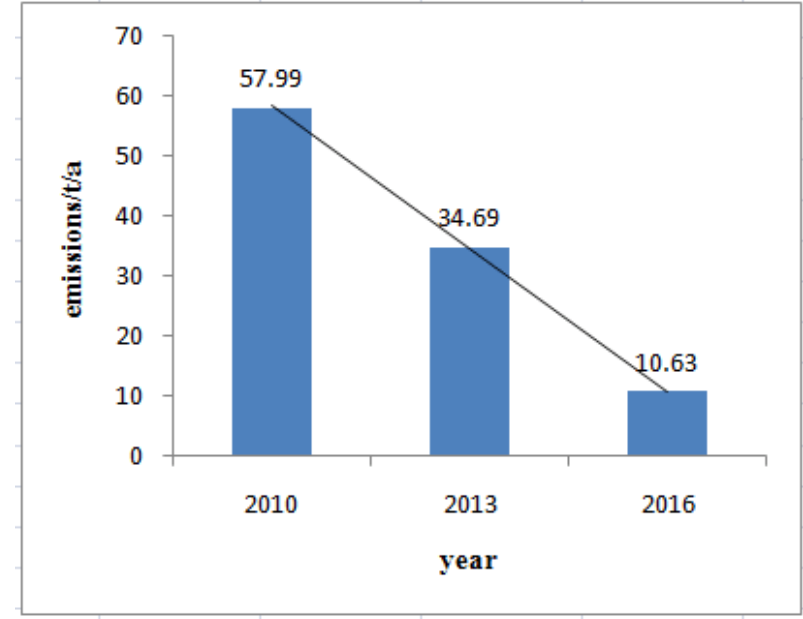

Fig 4 Changes in emissions of lead

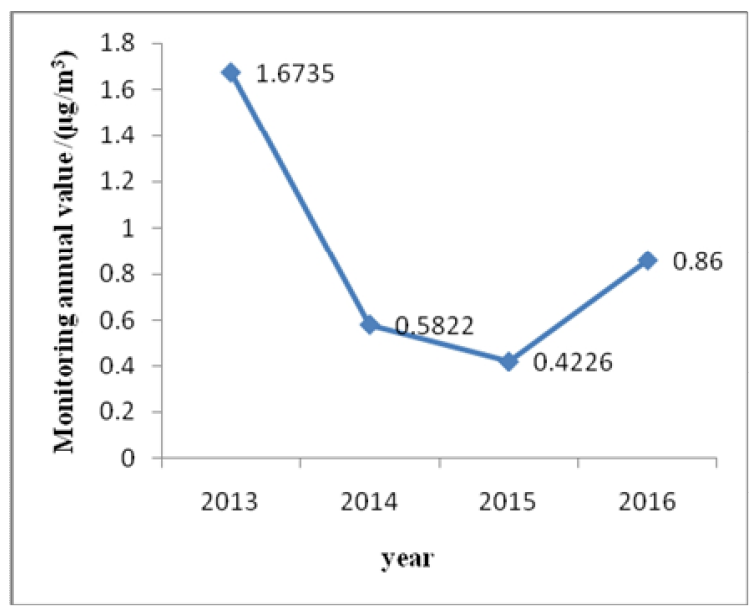

Fig 5 Changes in monitoring data of lead

Despite significant improvements in lead emissions, atmospheric monitoring values, and population health, the monitoring annual value in 2016 did not meet the Class 2 limit values $\left(0.5 \mu \mathrm{g} / \mathrm{m}^{3}\right)$ of the 《Ambient Air Quality Standards of the People's Republic of China》(GB3095-2012) (see figure 6). The monitoring annual value of lead in 2016 was $0.86 \mu \mathrm{g} / \mathrm{m}^{3}$ with the exceeding rate of 0.72 . The proportion of children with high lead levels also reached $50 \%$. These revealed serious pollution in this region.

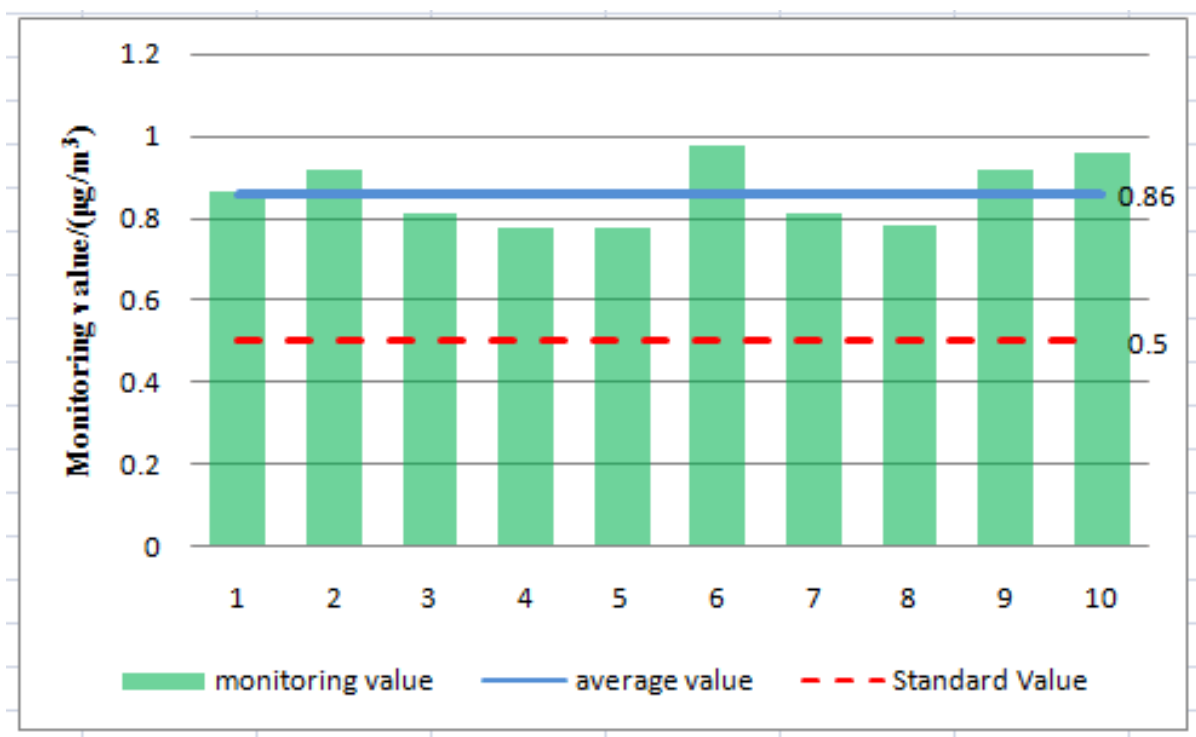

Fig 6 monitoring data of lead in2016

By investigation and interview, we find that the measures have not been fully implemented. There were 50 items for reducing heavy metals, 43 of them completed and 7 were not completed, and the completion rate was $86 \%$. The relocation population was 12,900 ; however, 3,328 people remained in this area, accounting for $25.8 \%$ of the total.

The calculation of the atmospheric environment capacity of the regional of lead is too simple. The capacity was calculated by using A-P method in Technical methods for making local emission standards of air pollutants (GB /T3840 - 91). This method has advantages of simple formula, less parameter and convenient calculation, however, the formula did not take into account climate, dry and wet deposition and pollutant attenuation. It can only be used for a rough analysis of a region's pollutant capacity. The environmental capacity of lead was as high as 104t/a in the planning EIA report. In reality, the monitoring annual value of lead in 2016 was $0.86 \mu \mathrm{g} / \mathrm{m}^{3}$ with the exceeding rate of 0.72 , but emissions were only 10.63t/a. 


\section{Suggestion}

Through the case analysis we found that the lack of planning and planning EIA often leads to chaotic and disordered development in the region. To ensure early implementation of the planning EIA, planning environmental impact assessment classification management directory should be carried out by ministry of environmental protection as soon as possible. In the directory, it is necessary to specify which plans need to carry out planning EIA. The category, approval level and responsibility subject of the planning EIA should be clearly explained. The communication and coordination with planning units, planning approval units and their related integrated management departments and industry management departments should also be strengthened.

Planning EIA tracking evaluation should be normalized. Further argumentation and review of the constraint conditions, environmental protection measures and rectification suggestions proposed in the planning EIA are carried out through tracking evaluation. The results of the planning EIA monitoring and forecast analysis need to be reassessed. Through regular tracking and evaluation, ensure the implementation and revise the uncertainty of planning EIA.

As a regular system, Planning EIA tracking evaluation should be carried out on a regular basis. But for the major environmental issues that occurred during the period, an emergency verification regime is essential. Timely verification of the major adverse environmental impacts arising from the implementation of the plan should be conducted by department of environmental protection. At present, the verification regime has not yet been formally to carry out. The indications of major environmental problems and the starting mechanism of verification should be determined. Technical guidelines should be introduced as soon as possible.

\section{Conclusions}

A system including planning EIA, planning EIA tracking evaluation and verification regime should be established. Planning EIA plays a role in prevention and design. To ensure the implementation and revise the uncertainty of planning EIA, Planning EIA tracking evaluation should be carried out on a regular basis. In order to solve the major adverse environmental impacts arising from the implementation of the plan timely, an emergency verification regime is essential.

\section{Acknowledgements}

This work was financially supported by "the verification for the major adverse environmental impacts arising from the implementation of the plan"(2110102) entrusted by the environmental impact assessment division of Ministry of Environmental Protection.

\section{References}

[1] H.Q. Geng: Handicap of China's Plan Environmental Impact Assessment and the Countermeasures[J] Environmental Science \&Technology Vol. 35 (2012), p.368-372. (in Chinese)

[2] N. Lee, F. Walsh: Strategic environmental assessment: an overview [J].Project Appraisal Vol. 7( 3) (1992), p.126-136.

[3] Alan Bond, Thomas B Fischer, Josh Fothergill: Progressing quality control in environmental impact assessment beyond legislative compliance: An evaluation of the IEMA EIA Quality Mark certification scheme Environmental Impact Assessment Review Vol. 63, (2017), p.160-171

[4] Y.B. Qi. Progress of resources \& environment carrying capacity research and the main problems [J]. Resources Economics, Vol. 5 (2005), p.: 7-11. (in Chinese) 
[5] H. Zhang. Comment on resources \& environment carrying capacity research [J]. Theory Journal, Vol. 164 (2007), p.: 80-83. (in Chinese) 